\title{
Microstructure change in wood cell wall fracture from mechanical pretreatment and its
}

\section{influence on enzymatic hydrolysis}

\author{
Jinxue Jiang a, Jinwu Wang b, Xiao Zhang c, Michael Wolcotta, * \\ b Composite Materials and Engineering Center, Washington State University, Pullman, WA, 99164, USA \\ a Forest Products Laboratory, United States Department of Agriculture Forest Service, Orono, ME, 04469, USA. \\ c Voiland School of Chemical Engineering and Bioengineering, Washington State University, Richland, WA, \\ 99354, USA \\ *Corresponding author. Tel.: +1 (509)-335-6392. E-mail: wolcott@wsu.edu (M. Wolcott).
}

\begin{abstract}
Mechanical pretreatment is an effective process for chemical or biochemical conversion of woody biomass. The deconstruction features of the wood cell wall play an important role in its chemical or biochemical processing. In this work, we evaluated the wood
\end{abstract} cell wall fracture in the early stage of mechanical pretreatment process conducted with various initial moisture contents. Electronic microscopy (i.e., SEM and TEM) and confocal laser scanning microscopy (CLSM) were used to visualize the cellular structure changes due to cell wall fractures. Results reveal that the enzymatic digestibility of micronized wood produced from different initial moisture contents was improved by 2-6 folder than that of the raw material. The types of cell wall fractures after mechanical pretreatment were distinguished by the initial moisture contents of wood. In wood samples with lower moisture content, interwall fracture occurred predominantly at the middle lamella region, while intrawall fracture occurred primarily at inner cell wall layers, with sever breakage in wood fibers for high moisture content samples. Differences in the distribution of surface chemical composition also resulted from different cell wall fractures. Lignin preferentially covered the fracture surface of low-moisture content samples, while carbohydrates were more predominate in high-moisture content samples. These morphological and structural alternation contributed to improving enzymatic digestibility of micronized wood. Findings from this study demonstrate how mechanical pretreatment modifies the fracture features of wood cell wall for further chemical/biochemical reactions. 
Key words: Mechanical pretreatment, cell wall fracture, morphology, structure, digestibility, energy efficiency, wood

\section{Introduction}

Currently, there is great interest in utilizing lignocellulosic biomass as a global energy source to reduce reliance of modern societies on fossil resources and mitigates greenhouse gas emissions. However, complex macromolecular interaction networks among biopolymer components in the plant cell wall matrix create natural recalcitrance. This, in turn, technically and economically limits the cost-effective release of fermentable sugars for subsequent liquid biofuels production (Zhao et al., 2012). The effectiveness of enzymatic saccharification of biomass is intricately related to their inherent properties, such as structural and chemical characteristics. Significant particle size reduction after pretreatment has been found to improve enzyme accessibility and mass/heat transfer efficiency (Zhao et al., 2012). The distribution of chemical composition is also integral to subsequent digestibility or a post pretreatment if required. Zhu et al., (2009) found that wood fiber with surface exposure of cellulose after chemimechanical pretreatment was more effective than wood fiber with lignin covering the surface in terms of subsequent enzymatic hydrolysis. Ju et al., (2013) found that, despite a similar bulk lignin content in wood fibers, the variation of surface lignin after chemical pulping pretreatments directly affected enzyme adsorption kinetics and hydrolysis rate.

From an anatomical viewpoint, the wood cell wall is composed of a hierarchical ultrastructure assemble ranging from the molecular level to micrometers cell wall level (Chundawat et al., 2011). Adjacent cells are separated by the middle lamella, while the individual cell wall is typically composed of three layers (i.e., the middle lamella, primary cell wall, and secondary cell wall). The secondary cell wall can be further divided into sublayers (i.e., 
S1 outer, S2 middle, and S3 inner layer), with different self-assembly and hierarchical organization (Chundawat et al., 2011). In the layered cell wall, semi-crystalline cellulose microfibrils are assembled as the reinforcement structure and coated with amorphous hemicellulose-lignin matrix through hydrogen bonds or covalent bonds. In addition, the distribution of chemical composition is heterogeneous throughout the cell wall. For example, the highest concentration of lignin can be found in the middle lamella area (especially cell wall corner), while S2 layer has the highest concentration of cellulose (Panshin and DeZeeuw, 1970). Thus, it is conceivable that mechanical action on wood cell wall deconstruction would result in substrates with distinguished morphological and physicochemical characteristics.

In the mechanical pulping process, wood fiber fibrillation has been found to affect the characteristics of pulps, such as fiber length, aspect ratio and surface composition. These characteristics drastically impacted subsequent post treatment and final performance of paper (Fernando, 2007; Zhu, 2011). Mechanical pretreatment aimed at overcoming the recalcitrant structure to facilitate enzymatic saccharification differs from traditional mechanical pulping processes because maintaining fiber integrity is not necessary for sugar production. Considerable research has focused on maximizing fermentable sugar release by disrupting biomass cell wall structure after mechanical pretreatment (Inoue et al., 2008; Takahashi et al., 2013; Zakaria et al., 2014). In fact, the fracture of fiber bundles and the fragmentation of individual fibers at specific positions during the early stage of mechanical pretreatment may significantly affect substrate properties and/or post-treatment requirements for improving enzymatic hydrolysis (Ju et al., 2013; Zhu et al., 2009). However, there is still a research gap in the literature addressing the fundamental characteristics of cell wall fracture and the corresponding influence on surface chemical composition and enzymatic hydrolysis. 
In addition, mechanical pretreatment is generally considered to be energy intensive, which elicits particular attention for scaling bioconversion systems (Zhu, 2011). Studies show that energy consumption in mechanical wood pulping depends significantly on the mechanism of the wood fractured (Gorski, 2010a; Walter, 2009). The energy input for the mechanical refining process also affects final morphological and structural properties of wood fibers, e.g., fiber length/width and fineness (Fernando et al., 2011; Gorski, 2010b). However, additional research is needed to elucidate the fundamentals of wood cell fracture and its corresponding energy consumption during mechanical pretreatment.

This study is aimed at obtaining a better understanding of the structural and morphological characteristics of cell wall fractures of wood in the early stage of mechanical pretreatment and the influence of these characteristics on enzymatic hydrolysis. The influence of moisture content on the type of cell wall fracture in micronized wood is examined with a series of characterization techniques. These included electronic microscopy to delineate the structural changes in wood cell wall and, as it turned out, to reveal surface morphology and ultrastructural features of fractured cell walls. Fluorescence microscopy was applied as a rapid, effective way to identify and classify the fracture surface chemical composition distribution of micronized wood after mechanical pretreatment. We also evaluated the enzymatic hydrolysis of micronized wood and energy consumption of the mechanical pretreatment process in an effort to assess the change in the recalcitrance corresponding to wood cell wall fracture. Together, these data were integrated to provide insight into overcoming woody biomass recalcitrance for producing digestible substrate with mechanical pretreatment, or a combination of a second chemical treatment.

\section{Materials and methods}




\subsection{Materials}

Douglas-fir (Pseudotsuga menziesii) wood chip was obtained locally (Vaagen Brothers Lumber Inc., Colville, WA). Prior to pretreatment, the received chips were passed through a vibrating screen with $25.4-\mathrm{mm}$ aperture and then hammer-milled to pass a $3.18-\mathrm{mm}$ screen. The pre-processed feedstock was subsequently conditioned to different equilibrium moisture content (EMC) values (i.e., 5-30\%, dry weight). Before conducting fine milling pretreatment, all conditioned material was stored in sealed plastic bags and the moisture content was validated using gravimetric methods according to standard protocol (Sluiter et al., 2008a).

\subsection{Mechanical pretreatment process}

Mechanical milling pretreatment of woody feedstock was performed using a high-energy vibratory Standard Ring and Puck mill with motor power of 1.1-kw (Rocklab Pty Ltd, New Zealand). The milling chamber had an inner diameter of 128-mm and height of 43-mm. The grinding media were a ring (inner diameter 78-mm, outside diameter, 100-mm, height 41-mm) and a puck (diameter 52-mm and height 41-mm). Both milling chamber and grinding media were made of tungsten carbide. The samples (10-g, oven-dry base) with different moisture content were loaded to the milling chamber and milled for 2 minutes. The milling time was chosen based on preliminary test showing that the particle size of the milled substrate for 2-minutes milling was in the micrometer range with a discernable cell wall structure. Thus, the milled samples were also noted as micronized wood (or micronized particles) in this study.

\subsection{Measurement of specific energy consumption}

The specific energy consumed during mechanical milling process was measured using a Fluke 1735 power logger (Fluke, USA). The active power, active energy, power factor, 
frequency, and time were acquired by a computer. The specific energy consumption was calculated according to the following equation:

$E_{p}=\int_{0}^{t}\left(P_{t}-P_{0}\right) d_{t} / m=\int_{0}^{t} \Delta P_{t} d_{t} / m$

where: $E_{p}$ is the specific net energy consumption $(\mathrm{kJ} / \mathrm{kg}) ; P_{t}$ is the power consumed at time $\mathrm{t}$; $P_{0}$ is the average power consumption under idle condition measured from an empty mill; and $\mathrm{m}$ is the mass charge in $\mathrm{kg}$ of wood to be pulverized. All measurements were performed in duplicate.

\subsection{Composition analysis of the wood sample}

The chemical composition of wood material was assessed according to the two-step acid hydrolysis procedure from the NREL standard protocol (Sluiter et al., 2008b). Briefly, a 300-mg sample and 3-mL of $72 \% \mathrm{H}_{2} \mathrm{SO}_{4}$ was added to a $100-\mathrm{mL}$ pressure tube and incubated at $30{ }^{\circ} \mathrm{C}$ for 1 hour and stirred every 15 minutes. The sample was then diluted with $84 \mathrm{~mL}$ deionized water and autoclaved for 1 hour. Sugars were detected using a high-performance anion exchange chromatography (HPAEC) (Dionex, ICS-3000) as described below.

\subsection{Enzymatic hydrolysis}

Enzymatic hydrolysis was performed with 15 FPU/OD g of substrate Cellic CTec2 cellulase and cellic HTec2 hemicellulase (1/9 of the cellulase amount). Digestion was carried out in $125-\mathrm{mL}$ flasks with a citrate buffer $(\mathrm{pH} 4.8)$ at a solid loading of $2 \%$. The flasks were settled in an incubator with a rotation speed of $180 \mathrm{rmp}$ at $50^{\circ} \mathrm{C}$. After digestion of 72 hours, the hydrolysate was analyzed by HPAEC. Glucan and xyl/mannan conversions were defined as the percentage of glucose and xyl/mannose released compared to the theoretical maximum. Six replicates were conducted for each sample for statistical analysis.

Sugars measurements before and after enzymatic hydrolysis were performed using HPAEC (ICS-3000, Dionex, Sunnyvale, California) with ED 50 electrochemical detector 
(Dionext Corp., Bannockburn, IL, USA). Sugars were separated on a CarboPac PA 20 Guard $(4 \times 50-\mathrm{mm})$ and analytical columns $(4 \times 250-\mathrm{mm})$ at room temperature $\left(25^{\circ} \mathrm{C}\right)$. Then, $10-\mu \mathrm{L}$ of sample solution were injected into the HPAEC system to quantify the content of monosugars. The mobile phases were deionized water and 50-mM aqueous sodium hydroxide solution at a flow rate of $0.5-\mathrm{mL} / \mathrm{min}$. The detector was maintained at a $\mathrm{pH}$ of 10.4 . An AS40 sampler (Dionext Corp.) was used for continuous running and Dionex PeakNet 5.1 chromatography software was used for analysis of results

\subsection{Particle size distribution}

The volumetric particle size distribution of the micronized wood was determined using a laser scattering particle size analyzer Mastersizer 3000 with Hydro LV wet sample dispersion (Malvern instrument, UK). The median size $\left(\mathrm{D}_{50}\right)$ was used to represent the particle size for analysis.

\subsection{Dye adsorption and cellulose specific surface area}

Specific surface area of cellulose was measured by Congo red dye adsorption experiments as described elsewhere (Inglesby and Zeronian, 2002). In brief, Langmuir-type adsorption of a mono disperse dye DR28 (Congo red) was obtained on 1\% wood substrate in 0.03-M phosphate buffer ( $\mathrm{pH}$ 6) with 1.4-mM sodium chloride and an incubation temperature of $60{ }^{\circ} \mathrm{C}$. Suspensions were prepared with a series of increasing dye concentrations and incubated for 24 hours at $180 \mathrm{rpm}$. After incubation, each suspension was centrifuged for 5 minutes at $740 \mathrm{~g}$ and the absorbance of the supernatant was measured using UV-VIS spectrophotometer (Lambda 25 , PerkinElmer) at a wavelength of $498 \mathrm{~nm}$. The Langmuir maximum adsorption capacity was determined according to the equation described below (Wiman et al., 2012):

$\frac{[C]}{[A]}=\frac{1}{K_{a d s}[A]_{\max }}+\frac{[C]}{[A]_{\max }}$ 
where $[\mathrm{C}](\mathrm{mg} / \mathrm{mL})$ is the free dye concentration at equilibrium, $[\mathrm{A}](\mathrm{mg} / \mathrm{g})$ is the amount of dye adsorbed by the substrate, $[A]_{\max }$ is the maximum amount of dye adsorbed onto cellulose $(\mathrm{mg} / \mathrm{g})$, and $K_{a d s}$ is the adsorption equilibrium constant. The cellulose specific surface area (SSA) can be calculated from the following relation (Goodrich and Winter, 2007):

$S S A=[A]_{\text {max }} \times N_{A} \times S A_{C R} / M W$ where $N_{A}$ is Avogadro's constant, $S A_{C R}$ is the surface area of one molecule of Congo Red (1.73 $\left.\mathrm{nm}^{2}\right)$, and $M W$ is the molecular weight of Congo red $(696.7 \mathrm{~g} / \mathrm{mol})$.

\subsection{Scanning electron microscopy (SEM)}

SEM images of samples were acquired at 20-kV accelerating voltage using a FEI Quanta 200F, field emission gun with high vacuum ETD detectors (FEI Company, Hillsboro, Oregon, USA). Samples were mounted on aluminum stubs using carbon tape and sputter coated with 8 $\mathrm{nm}$ of gold for good conductivity prior to imaging.

\subsection{Sample embedding and sectioning}

Wood samples were prepared using microwave electronic microscopy processing. Samples were fixed in 3\% glutaraldehyde, and buffered in 0.05-M Pipes buffer (Sigma, St Louis, MO) with a microwave on full power. Dehydration was conducted in graded ethanol series for 40 seconds under microwave at 30\%, 50\%, 60\%, 70\%, 80\%, 90\%, and 3×100\% ethanol. Samples were infiltrated with Spurr's low viscosity resin and incubated overnight at room temperature in a hood with increasing concentration of the resin $(30 \%, 50 \%, 3 \times 100 \%$ resin, diluted in isopropanol). Samples were then transferred to $1.5-\mathrm{mL}$ micro-centrifuge tubes with fresh Spurr's resin. The resin was then polymerized overnight in an oven with a temperature of $70{ }^{\circ} \mathrm{C}$. Embedded samples were sectioned to $300 \mathrm{~nm}$ for light microscopy and to approximately 90nm for TEM with a Diatome diamond knife was used to obtain the sections on a Leica Reichert Ultracut R microtome (Leica, Wetzlar, Germany). 


\subsection{Confocal laser scanning microscopy (CLSM)}

Semi-thin $(300 \mathrm{~nm})$ sample sections were positioned on glass microscope slides and stained with saturated HPLC-grade acridine orange (AO; 3, 6-bis (dimethylamino) acridine hydrochloride, Sigma-Aldrich, St. Louis, MO) for 1 hour at room temperature. The images of stained samples were captured using a Leica TCS SP8 confocal scanning laser microscopy with a $40 \times$ oil objective lens. A white laser at $\lambda=500 \mathrm{~nm}$ was used as the excitation light source. Fluorescence emission between $\lambda=515$ and $540 \mathrm{~nm}$ were collected as the green channel and emissions above $\lambda=590 \mathrm{~nm}$ were collected as the red channel. Image analysis was performed using LAS AF Lite imaging analysis software. The images that appeared green in color were rich in carbohydrates, and areas that were red in color were rich in lignin. Furthermore, multiple line scans across cell walls and wall fragments at various mechanical milling time points were also analyzed to investigate the lignin/carbohydrates redistribution. The signal intensity represented as raw pixel intensity and distance as the pixel distance.

When AO interacts with carbohydrates, it remains in a monomeric form which fluoresces and emits light primarily in the green region of the visible light spectrum. However, when AO interacts with the aromatic $\pi$ electrons of lignin, the electron density of the molecule changes in such a way that causes other AO molecules to aggregate. This causes a fluorescence emission shift from the green to red light spectrum.

\subsection{Transmission electron microscopy (TEM)}

Ultrathin sections (90nm) were collected on Formvar coated copper slot grids (SPI Supplies, West Chester, PA). Grids were post-stained for 10 minutes with $1 \%$ aqueous $\mathrm{KMnO}_{4}$ to selectively stain for lignin. Images were captured with a 4 megapixel Gatan UltraScan $4 \mathrm{~K}$ 
Eagle camera (Gatan, Pleasanton, CA) on a FEI Tecnai G2 20 Twin 200kV LaB6 TEM (FEI, Hilsboro, OR).

\subsection{Calculation of intra-cell wall void space}

Cell wall void space created by mechanical deconstruction of the cell wall integrity was quantified by processing TEM micrographs to threshold intra-wall void spaces into regions from which size and shape of voids could be obtained, as described elsewhere(Ciesielski et al., 2014; Ji et al., 2015). Six regions of interest (ROI) from six different images of samples from each initial moisture content were analyzed for determination of void space. Thresholds that would distinguish void spaces from intact cell wall regions were first determined by obtaining the mean and standard deviation of pixel values within a ROI containing only void space, such as the cell lumen. The threshold was then determined as the pixel value of two standard deviations above from the mean pixel value of the designated void region as following equation: $T=\bar{m}_{v}+2 \sigma_{v}$ where $\mathrm{T}$ is the threshold value, and $\bar{m}_{v}$ and $\sigma_{v}$ are the mean and standard deviation of pixel values from a known void region. Examples measuring ROIs of intra-wall regions and the corresponding binary images determined with this thresholding methodology are demonstrated in Figure 7b. Image processing was conducted with ImageJ software (National Institutes of Health, USA).

\subsection{Statistical analysis}

All statistical analyses were carried out using SAS 9.0 statistical software package (SAS Institute Inc., Cary, NC). Results are reported as their means \pm SD. Analysis of variance (ANOVA) were performed to test the significance of treatments. The Tukey's method was conducted to distinguish the difference among multiple treatment means. All significant levels were set at 0.05 . 


\section{Results and discussion}

\subsection{Digestibility of micronized wood}

Enzymatic digestibility strongly relates to pretreatment effectiveness and is considered to be an excellent probe for assessing cellulose accessibility and susceptibility to depolymerization catalysts (Ji et al., 2015). Micronized wood samples with different initial moisture contents during mechanical pretreatment were digested with commercial enzymes, and results are shown in Fig.1. The raw material without pretreatment showed fairly low digestibility, with a theoretical glucan conversion of $6.11 \pm 0.48 \%$ and $x y 1 /$ mannan conversion of $3.67 \pm 0.32 \%$ (Fig. 1), demonstrating significant cell wall recalcitrance. In contrast, the different initial moisture content during this early stage of milling process allowed 2-6 folder increase $(\mathrm{p}<0.05)$ in the glucan conversion of micronized. Our previous study has also demonstrated that the glucan conversion of micronized wood with full mechanical processing (i.e. 12-minutes milling) could be as high as $90 \%$, which was 14 times higher than that of the raw material (Jiang et al., 2016). The $\mathrm{xyl} /$ mannan conversion of micronized wood also increases $3-5$ times $(\mathrm{p}<0.05)$ compared to that of the raw material (Fig. 1). Among the micronized wood samples, the enzymatic digestibility increases as the initial moisture content increases, although the samples with lower moisture contents (i.e. MC5\% and MC10\%) exhibit similar sugars conversion ( $>$ > 0.05) as shown in Fig.1. It is worthy to note that there was not any significant change in crystallinity of wood samples milled in the early stage as reported in our previous study (Jiang et al., 2016). In addition, Table 1 presents the chemical compositions of micronized wood, which indicates no significant change in bulk cell wall components during milling process $(\mathrm{p}>0.05)$. The results agree well with previous observations of seldom modification of cell wall constituents with various mechanical milling pretreatments (Sipponen et al., 2014; Takahashi et al., 2013). Thus, it may suggest that 
the difference in cell wall structure fracture may contribute to the variance of micronized wood digestibility. Therefore, we examined the structural and morphological features derived from cell wall fractures in order to find evidence for difference in digestibility.

\section{Insert Fig. 1 here}

Fig. 1. The enzymatic glucan (A) and xyl/mannan (B) conversion of raw and micronized wood with various initial moisture content (MC). Same superscripts within bars are not significant different $(p>0.05)$ by Tukey's test of multiple comparison after ANOVA tests.

Table 1 Chemical composition of micronized wood samples

\begin{tabular}{ccccccc}
\hline & Arabinan \% & Galactan \% & Xyl/mannan \% & Glucan \% & Lignin \% & Extractives \% \\
\hline Raw & $1.32 \pm 0.15$ & $2.69 \pm 0.35$ & $16.53 \pm 0.12$ & $45.18 \pm 0.17$ & $28.88 \pm 0.37$ & $1.12 \pm 0.11$ \\
MC5\% & $1.33 \pm 0.21$ & $2.68 \pm 0.23$ & $16.61 \pm 0.18$ & $44.97 \pm 0.25$ & $28.91 \pm 0.28$ & $0.98 \pm 0.21$ \\
MC10\% & $1.31 \pm 0.19$ & $2.61 \pm 0.26$ & $16.45 \pm 0.23$ & $44.85 \pm 0.27$ & $28.53 \pm 0.41$ & $1.08 \pm 0.17$ \\
MC15\% & $1.29 \pm 0.28$ & $2.86 \pm 0.38$ & $16.57 \pm 0.19$ & $45.21 \pm 0.18$ & $28.76 \pm 0.29$ & $1.14 \pm 0.09$ \\
MC30\% & $1.26 \pm 0.31$ & $2.58 \pm 0.28$ & $16.51 \pm 0.22$ & $44.67 \pm 0.29$ & $29.24 \pm 0.39$ & $1.05 \pm 0.18$ \\
\hline
\end{tabular}

\subsection{Particle size of micronized wood samples}

The volume-based particle size distribution (PSD) of micronized wood was measured using the laser diffraction technique, as shown in Fig. 2. The PSD of samples after mechanical pretreatment shifted to smaller particle size range than that of raw material (Fig. 2A). Although there is obvious overlap in the PSD among the samples with an initial moisture content (MC) of $5-15 \%$, the sample with a higher initial moisture content contained a larger fraction of small particles than the others. The distribution curves skewed to smaller size as moisture content increased (Fig. 2A). For the MC30\% sample, the reduction in particle size was substantially 
greater (Fig. 2A). Overall, there was significant reduction in particle size for all samples after mechanical pretreatment compared to the raw material. Fig. 2B illustrated significant influence of initial moisture content on median particle size reduction of micronized wood particles $(\mathrm{p}<$ 0.05). Here, the median particle size decreased from $754 \pm 17.3 \mu \mathrm{m}$ (raw material) to $115 \pm$ $11.1 \mu \mathrm{m}(\mathrm{MC} 5 \%), 95.9 \pm 6.4 \mu \mathrm{m}(\mathrm{MC10} \%), 83.6 \pm 4.9 \mu \mathrm{m}(\mathrm{MC} 15 \%)$ and $61.5 \pm 5.2 \mu \mathrm{m}(\mathrm{MC} 30 \%)$, respectively. The difference in median size for lower moisture content samples (i.e., MC5\% and $\mathrm{MC} 10 \%)$ is not significant $(\mathrm{p}>0.05)$, implying similar structure breakage during mechanical fragmentation process. Further increasing moisture contents during mechanical milling process leads to statistical decrease of particle size (Fig. 2B), suggesting that mechanical pretreatment was more destructive to the structural integrity of high-moisture wood than with the drier samples. The reason may attribute to different energy input for milling samples with different moisture contents. A higher moisture content requires more energy input and can cause much more severe structure fracture during milling process.

Mechanically fragmenting lignocellulosic biomass is a complex process that is often affected by the material physicochemical properties, fracture of cell walls, energy input, and/or interactions among these variables (Fernando, 2007; Pelletier et al., 2013; Zhu, 2011). In the thermomechanical pulping (TMP) process, studies showed that secondary cell wall fibrillation with higher energy refining created more severe breakage in finer wood fibers (i.e., smaller particle size) than fibrillation occurring at the middle lamella and/or primary cell wall with lower energy consumption (Fernando, 2007; Fernando et al., 2011). In the following sections, we will describe features of the cell wall fracture in the early stage of producing micronized wood and the energy requirements for the mechanical fragmentation process. 
Particle size is a key structural feature affecting enzymatic digestion of lignocellulosic biomass. Pretreatment involving decrease of particle size has been demonstrated to be a versatile means of ensuring cellulose digestible for all biomass feedstock (Barakat et al., 2015; Takahashi et al., 2013; Zakaria et al., 2014). Our results also indicate that particle size reduction improves the digestibility of softwood, arguably the most recalcitrant of biomass type.

\section{Insert Fig. 2 here}

Fig. 2. (A) Volume-based particle size distribution of micronized wood samples from different initial moisture contents (MC); (B) effect of MC on median particle size development. Same superscripts within bars are not significant different $(\mathrm{p}>0.05)$ by Tukey's test of multiple comparison after ANOVA test.

\subsection{Specific surface area of cellulose in micronized wood}

The specific surface area (SSA) of cellulose is an important factor affecting the enzymatic digestion of lignocellulosic biomass, since close contact between cellulose and cellulase (e.g., endoglucanese) is an essential step to initiate hydrolysis reactions (Yang et al., 2011). Lignocellulosic biomass is also known as a heterogeneous composite with cellulose chains embedded in the hemicellulose and lignin matrix (Zhao et al., 2012). The layer structure also results in a heterogeneous distribution of chemical compositions (i.e., cellulose, hemicellulose and lignin) at cellular level. Mechanically fragmenting the lignocellulosic biomass is a process that disintegrates the cellular integrity of heterogeneous composites by generating new surface area (Temmerman et al., 2013). Thus, the SSA of cellulose is closely linked to cell wall fracture and resulting composition exposure on the newly generated surface.

DR28 (Congo red), a dye for specifically binding to cellulosic substrate, was used to estimate the cellulose SSA of samples with different initial moisture contents during the milling 
process (Wiman et al., 2012). More dye adsorption indicates a more accessible cellulose surface area (Lee et al., 2009). Correlation coefficients for a linear fit of the free dye concentration versus the free dye concentration/dye on substrate produced values of 0.99 for all samples (data not shown here). This suggests close adherence to Langmuir behavior (Goodrich and Winter, 2007). Fig. 3 represents the dye adsorption isotherms and demonstrates that the dye binding behavior can be reasonably described by Langmuir adsorption theory. Compared to the raw material, the micronized particles show an increased capacity of dye adsorption (Fig. 3). This indicates the increase of exposed surface cellulose after mechanical pretreatment. The maximum amount of dye adsorption was calculated according to Langmuir equation. The cellulose surface area of micronized wood was calculated by using the maximum amount of dye adsorbed onto the particles and the specific surface area of the Congo dye molecule (Goodrich and Winter, 2007), as presented in materials and methods section. The calculation of cellulose surface area is based on the assumption that the dye adsorbs parallel to the surface of the substrates.

In this study, the cellulose SSA increased from $20.18 \mathrm{~m}^{2} / \mathrm{g}$ (raw material) to $31.24 \mathrm{~m}^{2} / \mathrm{g}$ (MC5\%), $36.17 \mathrm{~m}^{2} / \mathrm{g}(\mathrm{MC10 \%}), 42 \mathrm{~m}^{2} / \mathrm{g}(\mathrm{MC} 15 \%)$ and $52.17 \mathrm{~m}^{2} / \mathrm{g}$ (MC30\%), suggesting that the initial moisture content influenced the generation of accessible cellulose surface area during the mechanical milling process. Although this result may have been influenced by the particle size variation in the samples, another contribution may be the difference in cell wall fracture modes from the different moisture contents during the mechanical milling process.

It is illustrated in Fig. 4 that the cellular fracture of wood during mechanical milling as imaged with confocal laser scanning microscopy (CLSM), while line scans across adjacent cell walls and the cell wall fracture regions give a more quantitative measure of the variation of chemical composition distribution caused by mechanical fracture. Fig. 4A shows the typical 
composition distribution in intact cell walls of raw material with lignin rich in middle lamella and cell wall corner regions. With a low initial moisture contents (e.g., MC5\% or 10\%), the dislocation and delamination of individual fiber or fiber bundles occurred predominately at the middle lamella region, exposing this lignin rich area on the surface of micronized wood (note the red color on the fracture surface in Fig. 4A and B). For samples with higher moisture contents (e.g., MC30\%), severe cellular fracture was observed, with splits in adjacent fibers at the inner cell wall layer. This fracture mode likely exposed the embedded cellulose microfibrils on the fracture surface (Fig. 4D). The line scans also show higher carbohydrate signal intensity than signal of lignin on the fracture surface. These results indicate that particle size reduction with mechanical pretreatment may have been coincident with creating a difference in the surface composition distribution, influencing the accessible cellulose SSA. The difference in enzymatic hydrolysis efficiency highlights the important influence of cell wall fracture on the digestibility of micronized wood.

\section{Insert Fig. 3 here}

Fig. 3. Langmuir isotherms of raw and micronized wood samples as a function of initial moisture content (MC).

\section{Insert Fig. 4 here}

Fig .4. Confocal laser scanning microscopy (CLSM) reveals fracture surface chemical composition distribution of raw and micronized wood with various initial moisture contents (MC) during the milling process. Colors in the images show lignin with red and polysaccharides with green. Raw material (A) has typical intact cell walls and scan lines show distribution of lignin and polysaccharides across the adjacent cell walls. MC5\%(B) and MC10\% (C) samples indicate cell wall fracture at middle lamella and scan lines show majority lignin exposure on the fracture 
surface. MC15\% (D) and MC30\% (E) show exposure of polysaccharides majority on fracture surface due to fracture at secondary cell wall. ROI: region of interest.

\subsection{Fracture surface morphology of micronized wood}

Surface morphology of the micronized wood produced with different initial moisture contents were investigated using SEM technique (Fig. 5). Loosening fiber bundles while promoting fiber separation at the middle lamella regions was observed in the SEM micrographs for the low initial MC samples (Fig.5 A1-A3). Mechanically fragmenting the middle lamella regions resulted in considerable debris (see the double-heads arrow in Fig. 5 A3). With an increase in the initial MC (i.e., MC10\%), individual fiber and fiber bundles were the main products derived from intensive milling. Detailed investigation reveals that the cell wall fracture also preferentially occurred at the middle lamella and primary cell wall layer regions (see arrows as shown in Fig. 5 B2-B3). Observations of the MC15\% samples indicate that fiber separation and internal fracture coincidently occurred (arrows in Fig. 5 C2-C3). The cracks in the S1 layer indicate increased breakage in the fiber cell wall compared to samples with a lower initial moisture content. When the initial moisture content of the sample was 30\%, the micronized wood underwent the most severe fracture at the cell wall level, as shown in Fig.5 D1-D3. By observing the microfibril orientation, it is possible to distinguish that the breakage fractions also originated in the thicker inner S2 layer after intensive mechanical milling. The random split and fracture of fiber walls resulted in multi-directional breakage of structural cell walls. Qualitatively, the higher initial moisture content samples had a much rougher surface with severe breakage. This supports the above findings of increased cellulose SSA, suggesting that disruption of micronized wood surface may improve enzymatic digestibility. Mechanically fragmenting the inner S2 layer may also present benefits to the direct action of chemical pretreatments (e.g., 
disrupting cellulose structure with ionic liquid treatment, etc.), while fracture of middle lamella of the cell wall may facilitate delignification treatments.

Differences in the morphology of micronized wood surfaces may also reveal that different fractures govern the breakage of wood cell walls with different moisture contents during the early stage of mechanical pretreatment. Interwall fracture, or delamination and separation of fiber cell walls at the adjacent lamella regions, preferentially occurred for samples with low initial moisture content (i.e., MC 5\% and 10\%). Fracture transition from the outer to inner cell wall occurred for samples with MC15\% during the milling process. For the substrate with a high initial MC (i.e., MC30\%), intrawall fracture predominated the breakage of cell walls, leading to separation and delamination of structural cell wall layers.

The main chemical composition in the middle lamella and primary cell wall is ligninhemicellulose composites, an amorphous polymer (Srndovic et al., 2011). Moisture content is believed to be an important factor influencing the stiffness of wood polymer constitutions (Reiterer and Tschegg, 2002). In the low moisture content state, the amorphous polymer becomes brittle, resulting in easy fracture propagation at the middle lamella region. An increase in moisture content leads to increase in toughness of the amorphous polymer. Thus, with intensive mechanical action, the fracture may occur preferentially at the brittle cell wall layer, due to the high content of crystalline cellulose.

\section{Insert Fig. 5 here}

Fig. 5. Surface morphological features of wood fiber cell wall fracture with different moisture contents during the milling process; A1-A3 (MC5\%) showing fiber bundle delamination at adjacent middle lamella; B1-B3 (MC 10\%) showing fiber separation at primary wall and middle lamella; C1-C3 (MC15\%) showing fiber separation and 
breakage at the S1 layer; D1-D3 (MC30\%) showing fiber fracture at the S1 and S2 layers. A1-D1 scale bars are 50 $\mu \mathrm{m}$; A2-D2 scale bars are $25 \mu \mathrm{m}$; A3-D3 scale bars are $10 \mu \mathrm{m}$. Arrows show cell wall fracture, and double-head arrows show debris.

\subsection{Differences in the ultrastructure of micronized wood cell walls}

TEM analysis identified differences in the cell wall ultrastructure, distinguished by the initial moisture content after mechanical deconstruction, as shown in Fig. 6. When the initial moisture content was $5 \%$, dislocation of adjacent cell walls and delamination in the middle lamella caused individual fiber or fiber bundles to split (Fig. 6A). Cracks also occurred in the cell wall corners, suggesting easy fracture of brittle components for samples with the low moisture content. Fig. 6B indicates that delamination at the middle lamella/primary wall compound regions was the main breakage of MC10\% samples, which also contributed to fiber separation. Total or partial removal of the middle lamella and cell wall corners generated considerable fragment debris, as shown in SEM micrographs (double-heads arrow in Fig. 5A3 and B3).

There was little difference in the fracture surfaces of samples with these two lowest moisture content levels. As discussed above, relatively low moisture contents rendered high stiffness of the amorphous polymers, leading to brittle fracture during the mechanical treatment process (Reiterer and Tschegg, 2002). The typical secondary cell wall structure may still be discerned for sample MC15\% (Fig. 6C), but the middle lamella and primary cell wall interphase is split. It is hard to distinguish whether the outer surface is the S1 layer or S2 layer. With an increase in MC to $30 \%$, crack propagation and microfibrils delamination of the secondary cell wall could be detected in addition to the obvious peeling of the middle lamella region (Fig. 6D). The extent of loosening and fracturing in the cell wall structure was quantified by determining the intra-cell wall void spaces directly from TEM micrographs (as detailed in the methodology part). The results summarized in Fig. $7 \mathrm{C}$ clearly suggest that a higher moisture content in 
mechanical process lead to increasing in the degree of cell wall structural disruption displayed with formation of more intra-cell wall void spaces. The intra-void spaces presented in samples can also explain the increase of surface area permitting increased substrate accessibility for hydrolytic enzymes. Therefore, TEM imaging revealed that the fracture features of cell wall ultrastructure was in good agreement with the results of surface morphology indicated by SEM imaging. Therefore, the particle surface morphology and ultrastructure changes indicate that structural disruptions at the cell wall level may contribute to the improved the enzymatic hydrolysis of micronized wood.

\section{Insert Fig. 6 here}

Fig. 6. Ultrastructure variation of milled wood cell walls with different moisture contents (MC). A (MC5\%), B (MC10\%), C (MC15\%), D (MC30\%). Arrows show major fractures at specific positions of the cell wall; ccML=cell corner middle lamella, $\mathrm{ML}=$ middle lamella.

\section{Insert Fig. 7 here}

Fig. 7. Explanatory determination of void space ratio from TEM micrographs. (A) Original TEM micrograph of a region of cell wall from sample milled with $\mathrm{MC10 \%}$. The ROI denoted with asterisk designates the known void area from which the threshold value was calculated. (B) A binary version of the same image that delineates intra-wall void space from mechanical action and also shows how intra-wall ROIs selected from original image. (C) Results of intra-wall void measured by image analysis and presented as a ratio of the measured area.

\subsection{Energy efficiency of mechanical pretreatment}

The energy intensity of pretreatment is generally considered to play a vital role for the economical production of biofuels (Miao et al., 2011; Zhu and Zhuang, 2012). Table 1 indicates 
that the specific energy consumption of mechanical pretreatment process is differentiated by the initial moisture content of the wood. Energy consumption values for mechanical pretreatment increase from 0.079 to $0.358 \mathrm{kWh} \mathrm{kg}^{-1}$ as the initial moisture content increases. The significant difference in energy requirements may be attributed to differences in fractures of wood cell walls during mechanical pretreatment process. It is well understood that energy consumption in mechanical pulping is highly depending on the location of cell wall separation and fibrillation (Pelletier et al., 2013; Walter-Paulsson, 2009). The TMP process, in which wood fibers are fractured in the secondary cell wall (i.e., S1 or S2 layers) requires more energy than mediumdensity fiberboard (MDF) fiber fibrillation, in which fiber wall fracture and separation at the middle lamella region (Zhu, 2011).

Moisture content is known to be an important factor influencing the stiffness of cell wall amorphous components such as hemicellulose and lignin (Salmen and Olsson, 1998; Wolcott et al., 1990). At a low initial moisture content (e.g., MC 5\%), the brittle middle lamella appears to fracture easily with low energy consumption. As the initial moisture content increases to $10 \%$, energy is consumed to overcome the toughness of amorphous polymer before fracturing. This leads to greater energy consumption than was required by the MC5\%sample. When the initial moisture content increases further, the toughness of the amorphous polymers increases, since moisture acts as plasticizer. This results in more energy consumption with more rupture. Previous research indicated that TMP pulping process with high refining energy could increase the internal fibrillation of pulp fibers with more exposure of the S2 layer and generate more fines, compared to the products created using TMP pulping with low energy input (Fernando et al., 2011).

Table 2 Sugar yields of micronized wood and energy efficiency of mechanical pretreatment

\begin{tabular}{|c|c|c|c|c|c|}
\hline Samples Glucose yield & Xyl/mannose & Total sugar & Energy & Energy & Energy \\
\hline
\end{tabular}




\begin{tabular}{ccccccc}
\hline & $\mathrm{g} \mathrm{kg}^{-1}$ wood & $\begin{array}{c}\text { yield } \\
\mathrm{g} \mathrm{kg}^{-1} \text { wood }\end{array}$ & $\begin{array}{c}\text { yield } \\
\mathrm{g} \mathrm{kg}^{-1} \text { wood }\end{array}$ & $\begin{array}{c}\text { requirement for } \\
\text { milling } \\
\mathrm{kWh} \mathrm{kg}^{-1} \text { wood }\end{array}$ & $\begin{array}{c}\text { efficiency } \\
\mathrm{kg} \text { glucose } \mathrm{kWh}^{-1}\end{array}$ & $\begin{array}{c}\text { efficiency } \mathrm{kg} \\
\text { sugars } \mathrm{kWh}^{-1}\end{array}$ \\
\hline Raw & 31 & 7 & 38 & & & \\
$\mathrm{MC5} \%$ & 109 & 33 & 142 & 0.079 & 1.385 & 1.8 \\
MC10\% & 129 & 40 & 169 & 0.151 & 0.852 & 1.114 \\
MC15\% & 165 & 46 & 211 & 0.248 & 0.667 & 0.851 \\
MC30\% & 203 & 51 & 253 & 0.358 & 0.565 & 0.707 \\
\hline
\end{tabular}

In this present study, we evaluated the performance of mechanical pretreatment of woody biomass by calculating energy efficiency $\left(\mathrm{kg}\right.$ glucose $\left.\mathrm{kWh}^{-1}\right)$. The total amount of glucose obtained after enzymatic hydrolysis ( $\mathrm{kg}$ glucose/kg wood) was divided by the specific energy consumption for mechanical pretreatment ( $\mathrm{kWh} / \mathrm{kg}$ wood). Therefore, the higher value the higher energy efficiency. Table 2 indicates that energy efficiency decreases as initial moisture content increases, even though samples with higher moisture content resulted in more sugars yield. Thus, energy requirements for the pretreatment process are key factor related to processing conditions. On the other hand, utilization of hemicellulose can improve energy efficiency in the pretreatment process. This is evident in the higher energy efficiency values from the total sugar yield than from glucose yield (Table 2).

\subsection{Conclusions}

Initial moisture content differentiated the cell wall fracture in the early stage of mechanical pretreatment for wood samples. Cell wall fractures occurred predominantly in the middle lamella region for lower moisture content samples, while higher moisture content resulted in fracture of the secondary cell wall layers, with severe breakage for wood fibers. Difference in cell wall fractures led to difference in the surface chemical compositions and accessible area. The structural and morphological differences caused by the different types of 
cell wall fracture during mechanical process contributed to 2-6 times increase of enzymatic digestibility than that of the raw material.

\section{Acknowledgements}

The authors are grateful to the financial support from the Agriculture and Food Research Initiative (AFRI) Competitive grant (No. 2011-68005-30416), USDA National Institute of Food and Agriculture (NIFA) through the Northwest Advanced Renewables Alliance (NARA). The authors would also like to acknowledge the help of microscopic analysis from Franceschi Microscopy \& Imaging Center (FMIC) at Washington State University, Pullman.

\section{References}

Barakat, A., Monlau, F., Solhy, A., Carrere, H., 2015. Mechanical dissociation and fragmentation of lignocellulosic biomass: Effect of initial moisture, biochemical and structural proprieties on energy requirement. Appl. Energy 142, 240-246. doi:10.1016/j.apenergy.2014.12.076

Chundawat, S.P.S., Beckham, G.T., Himmel, M.E., Dale, B.E., 2011. Deconstruction of Lignocellulosic Biomass to Fuels and Chemicals. Annu. Rev. Chem. Biomol. Eng. 2, 121-145. doi:10.1146/annurev-chembioeng-061010-114205

Ciesielski, P.N., Wang, W., Chen, X., Vinzant, T.B., Tucker, M.P., Decker, S.R., Himmel, M.E., Johnson, D.K., Donohoe, B.S., 2014. Effect of mechanical disruption on the effectiveness of three reactors used for dilute acid pretreatment of corn stover Part 2: morphological and structural substrate analysis. Biotechnol. Biofuels 7, 1-12.

Fernando, D., 2007. Ultrastructural Characterization (Morphological and Topochemical) of Wood Pulp Fibres; Effect of Mechanical and Kraft Processes (Ph.D). Swedish University of Agricultural Sciences, Uppsala.

Fernando, D., Muhić, D., Engstrand, P., Daniel, G., 2011. Fundamental understanding of pulp property development under different thermomechanical pulp refining conditions as observed by a new Simons' staining method and SEM observation of the ultrastructure of fibre surfaces. Holzforschung 65, 777-786. doi:10.1515/HF.2011.076

Goodrich, J.D., Winter, W.T., 2007. $\alpha$-Chitin Nanocrystals Prepared from Shrimp Shells and Their Specific Surface Area Measurement. Biomacromolecules 8, 252-257. doi:10.1021/bm0603589

Gorski, 2010a. Review: Reduction of energy consumption in TMP refining through mechanical pre-treatment of wood chips. Nord. Pulp Pap. Res. J. 25, 156-161. doi:10.3183/NPPRJ2010-25-02-p156-161 
Gorski, 2010b. Review: Reduction of energy consumption in TMP refining through mechanical pre-treatment of wood chips. Nord. Pulp Pap. Res. J. 25, 156-161. doi:10.3183/NPPRJ2010-25-02-p156-161

Inglesby, M.K., Zeronian, S.H., 2002. Direct dyes as molecular sensors to characterize cellulose substrates. Cellulose 9, 19-29.

Inoue, H., Yano, S., Endo, T., Sakaki, T., Sawayama, S., 2008. Combining hot-compressed water and ball milling pretreatments to improve the efficiency of the enzymatic hydrolysis of eucalyptus. Biotechnol. Biofuels 1, 2. doi:10.1186/1754-6834-1-2

Ji, Z., Zhang, X., Ling, Z., Zhou, X., Ramaswamy, S., Xu, F., 2015. Visualization of Miscanthus $\times$ giganteus cell wall deconstruction subjected to dilute acid pretreatment for enhanced enzymatic digestibility. Biotechnol. Biofuels 8. doi:10.1186/s13068-015-0282-3

Jiang, J., Wang, J., Zhang, X., Wolcott, M., 2016. Evaluation of physical structural features on influencing enzymatic hydrolysis efficiency of micronized wood. RSC Adv 6, 103026103034. doi:10.1039/C6RA22371K

Ju, X., Engelhard, M., Zhang, X., 2013. An advanced understanding of the specific effects of xylan and surface lignin contents on enzymatic hydrolysis of lignocellulosic biomass. Bioresour. Technol. 132, 137-145. doi:10.1016/j.biortech.2013.01.049

Lee, S.-H., Teramoto, Y., Endo, T., 2009. Enzymatic saccharification of woody biomass micro/nanofibrillated by continuous extrusion process I - Effect of additives with cellulose affinity. Bioresour. Technol. 100, 275-279. doi:10.1016/j.biortech.2008.05.051

Miao, Z., Grift, T.E., Hansen, A.C., Ting, K.C., 2011. Energy requirement for comminution of biomass in relation to particle physical properties. Ind. Crops Prod. 33, 504-513. doi:10.1016/j.indcrop.2010.12.016

Panshin, A.J., DeZeeuw, C., 1970. Structure, identification, uses, and properties of the commercial woods of the United States and Canada, 3rd ed. McGraw-Hill, New York, NY, USA.

Pelletier, A., Zhao, Y., Lei, X., Li, K., 2013. Improved Fiber Separation and Energy Reduction in Thermomechanical Pulp Refining Using Enzyme Pretreated Wood. BioResources 8, 3385-3398.

Reiterer, A., Tschegg, S., 2002. The influence of moisture content on the mode I fracture behaviour of sprucewood. J. Mater. Sci. 37, 4487-4491.

Salmen, L., Olsson, A.-M., 1998. Interation between hemicelluloses, lignin and cellulose: structure-property relationships. J. Pulp Pap. Sci. 24, 99-103.

Sipponen, M.H., Laakso, S., Baumberger, S., 2014. Impact of ball milling on maize (Zea mays L.) stem structural components and on enzymatic hydrolysis of carbohydrates. Ind. Crops Prod. 61, 130-136. doi:10.1016/j.indcrop.2014.06.052

Sluiter, A., Hames, B., Hyman, D., Payne, C., Ruiz, R., Scarlata, C., Sluiter, J., Templeton, D., Wolfe, J., 2008a. Determination of total solids in biomass and total dissolved solids in liquid process samples. Natl. Renew. Energy Lab. Colo.

Sluiter, A., Hames, B., Ruiz, R., Scarlata, C., Sluiter, J., Templeton, D., Crocker, D., $2008 b$. Determination of structural carbohydrates and lignin in biomass. Lab. Anal. Proced.

Srndovic, J.S., Chalmers tekniska högskola, Chalmers tekniska högskola, Institutionen för kemioch bioteknik, Biopolymertechnologi, Innventia AB, 2011. Interactions between wood polymers in wood cell walls and cellulose/hemicellulose biocomposites. Chalmers University of Technology, Göteborg. 
Takahashi, T., Ito, K., Ito, A., Enda, Y., Gochi, M., Mori, H., Kobayashi, J., 2013. Tandem-ring mill pulverization benefits for enzymatic saccharification of biomass. Renew. Energy. doi:10.1016/j.renene.2013.07.046

Temmerman, M., Jensen, P.D., Hébert, J., 2013. Von Rittinger theory adapted to wood chip and pellet milling, in a laboratory scale hammermill. Biomass Bioenergy 56, 70-81. doi:10.1016/j.biombioe.2013.04.020

Walter, K., 2009. INFLUENCE OF ACID HYDROGEN PEROXIDE TREATMENT ON REFINING ENERGY AND TMP PROPERTIES (Licentiate of Technology). Mid Sweden University, Sundsvall, Sweden.

Walter-Paulsson, 2009. Energy efficient refining of black spruce TMP by using acid hydrogen peroxide: Part 1. A pilot plant study. Nord. Pulp Pap. Res. J. 24, 255-265. doi:10.3183/NPPRJ-2009-24-03-p255-265

Wiman, M., Dienes, D., Hansen, M.A.T., van der Meulen, T., Zacchi, G., Lidén, G., 2012. Cellulose accessibility determines the rate of enzymatic hydrolysis of steam-pretreated spruce. Bioresour. Technol. 126, 208-215. doi:10.1016/j.biortech.2012.08.082

Wolcott, M.P., Kamke, F.A., Dillard, D.A., 1990. Fundamentals of flakeboard manufacture: viscoelastic behavior of the wood component. Wood Fiber Sci. 22, 345-361.

Yang, B., Dai, Z., Ding, S.-Y., Wyman, C.E., 2011. Enzymatic hydrolysis of cellulosic biomass. Biofuels 2, 421-450. doi:10.4155/bfs.11.116

Zakaria, M.R., Fujimoto, S., Hirata, S., Hassan, M.A., 2014. Ball Milling Pretreatment of Oil Palm Biomass for Enhancing Enzymatic Hydrolysis. Appl. Biochem. Biotechnol. doi:10.1007/s12010-014-0964-5

Zhao, X., Zhang, L., Liu, D., 2012. Biomass recalcitrance. Part I: the chemical compositions and physical structures affecting the enzymatic hydrolysis of lignocellulose. Biofuels Bioprod. Biorefining 6, 465-482.

Zhu, J.Y., 2011. Physical Pretreatment-Woody Biomass Size Reduction-Forest Biorefinery, in: In Sustainable Production of Fuels, Chemicals, and Fibers from Forestr Biomass. American Chemical Society.

Zhu, J.Y., Wang, G.S., Pan, X.J., Gleisner, R., 2009. Specific surface to evaluate the efficiencies of milling and pretreatment of wood for enzymatic saccharification. Chem. Eng. Sci. 64, 474-485. doi:10.1016/j.ces.2008.09.026

Zhu, J.Y., Zhuang, X.S., 2012. Conceptual net energy output for biofuel production from lignocellulosic biomass through biorefining. Prog. Energy Combust. Sci. 38, 583-598. doi:10.1016/j.pecs.2012.03.007 

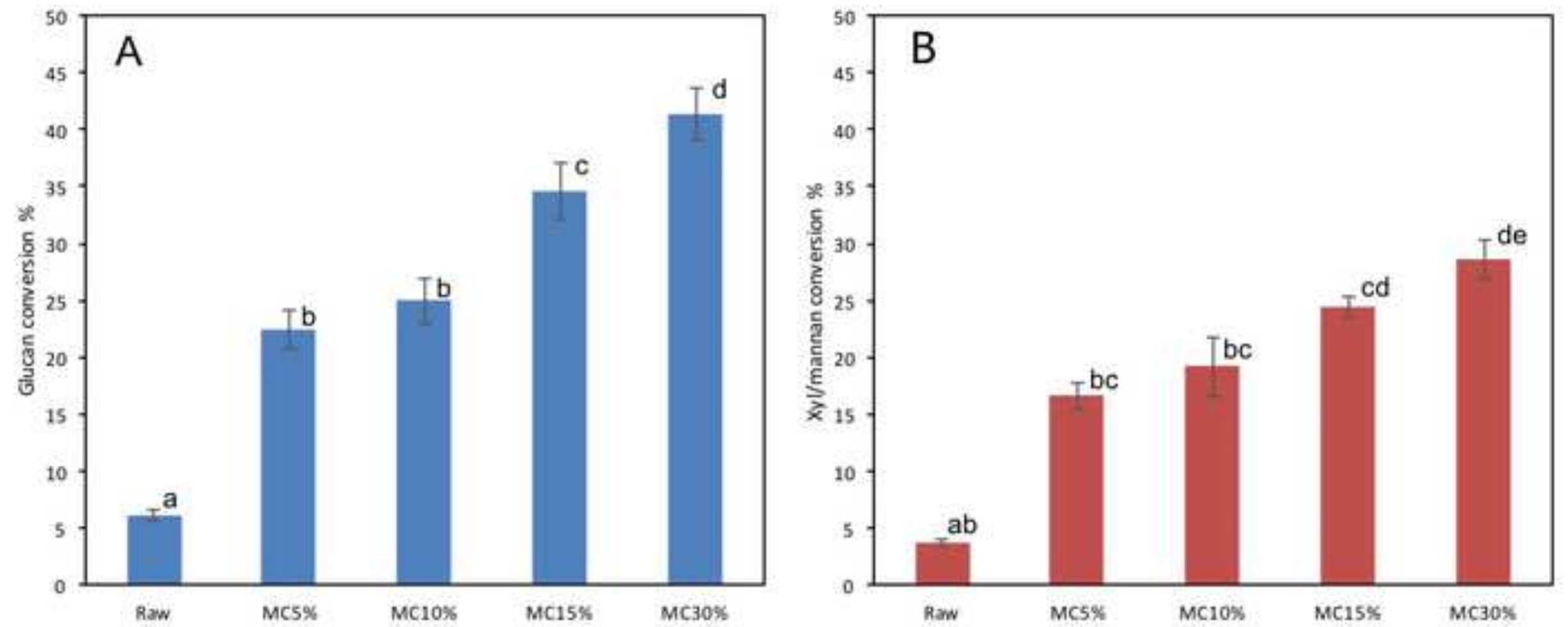

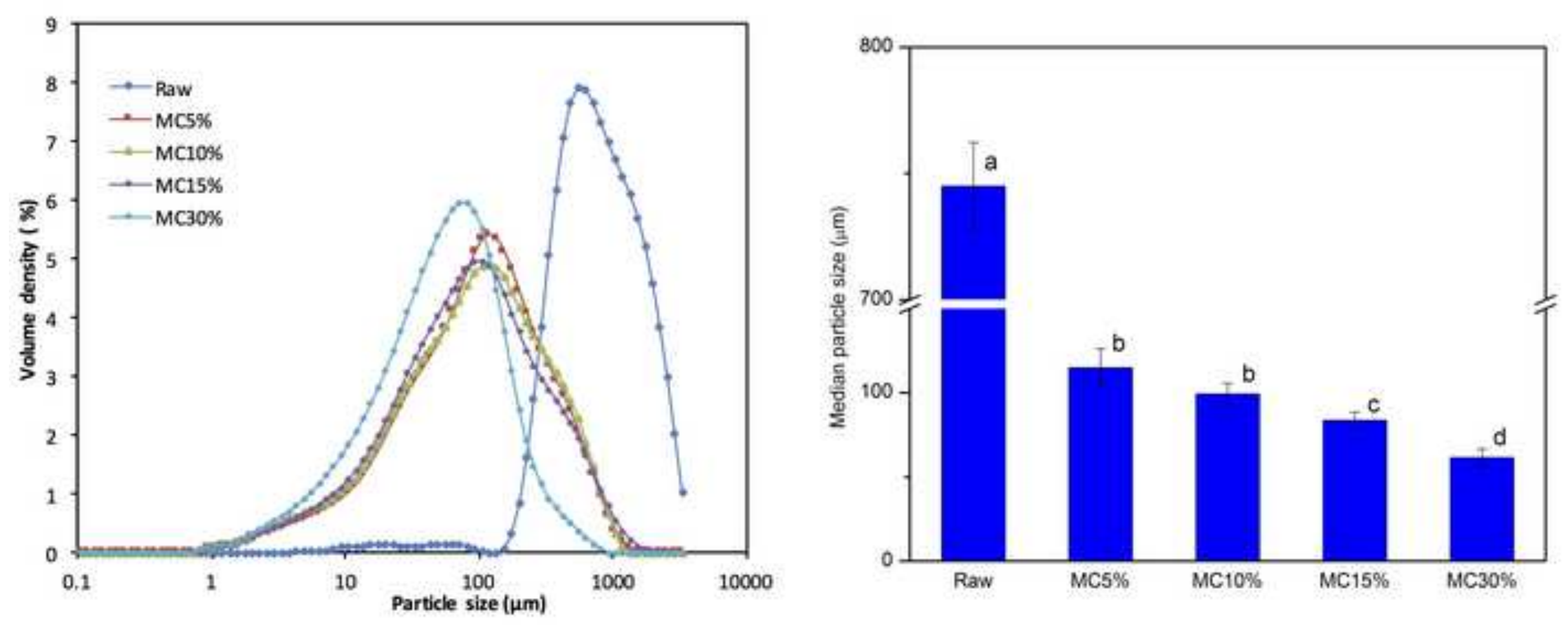

\section{Figure 2}




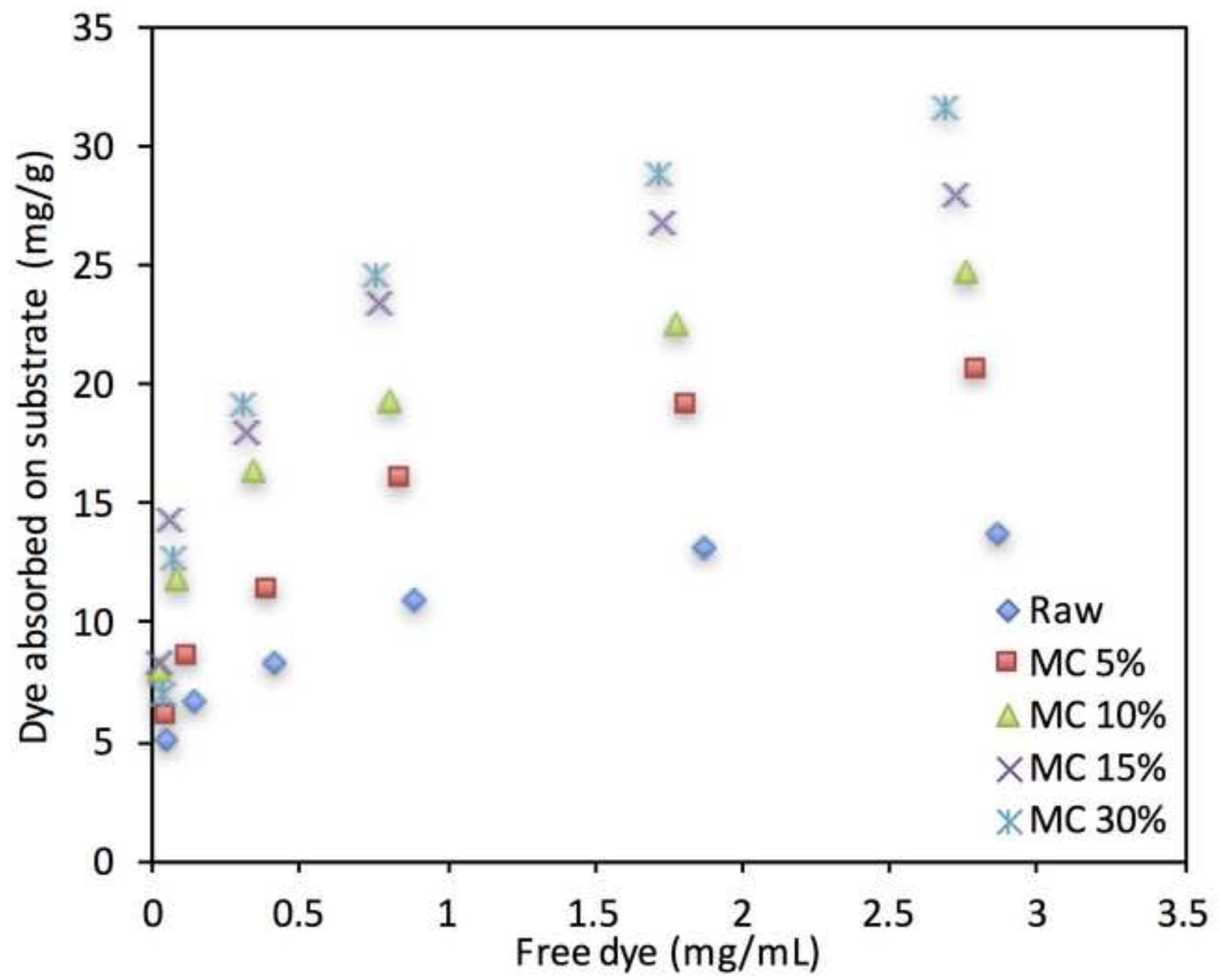



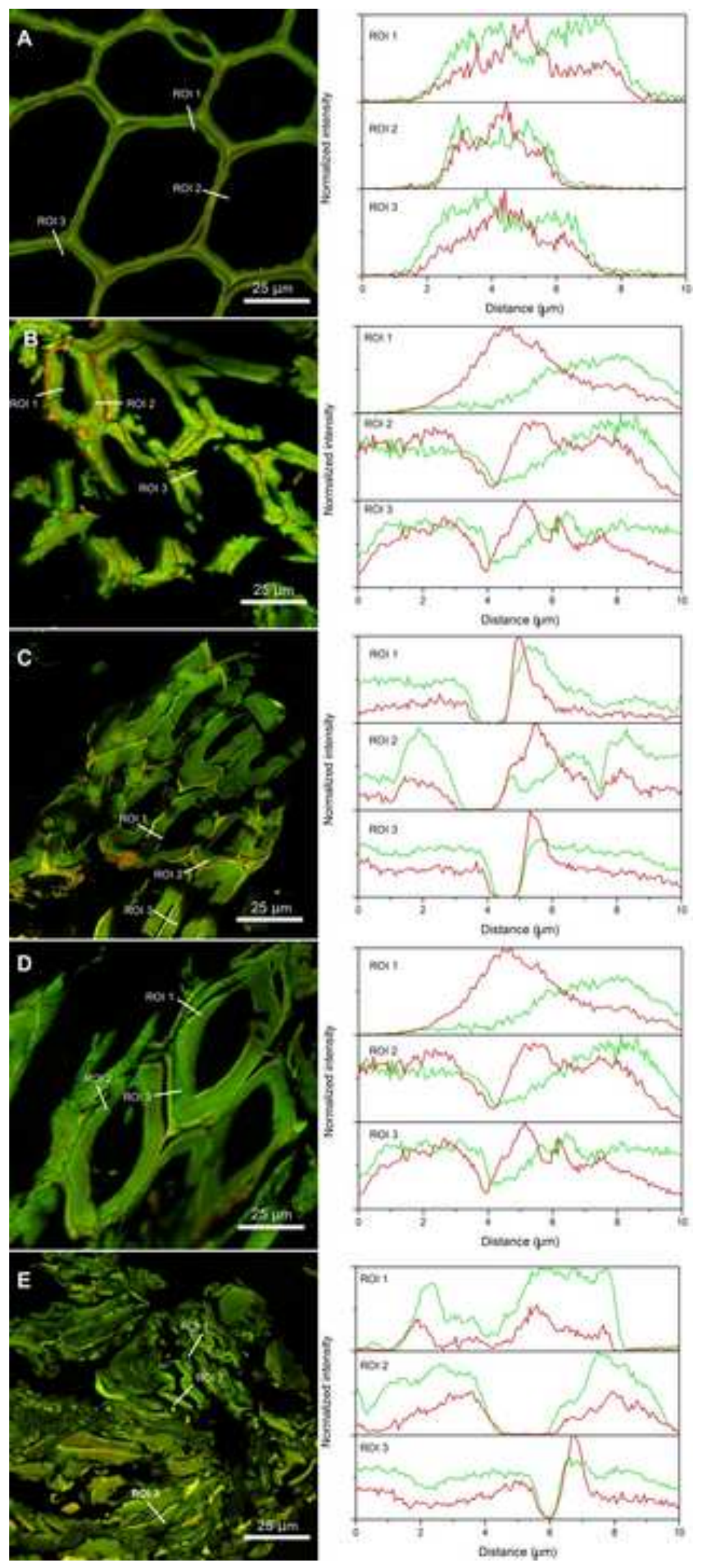


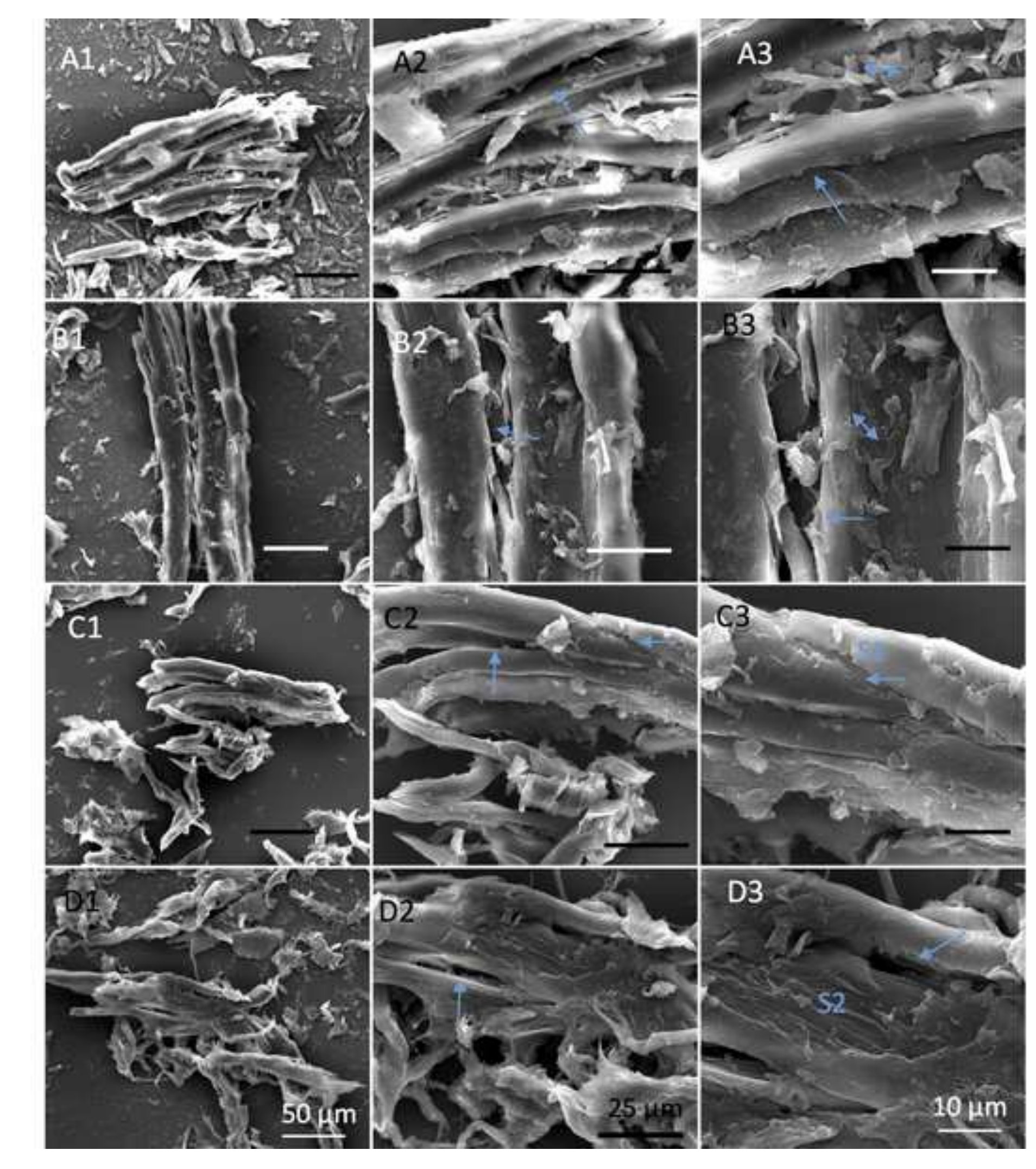

5

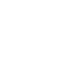

\begin{abstract}
$-$
\end{abstract}
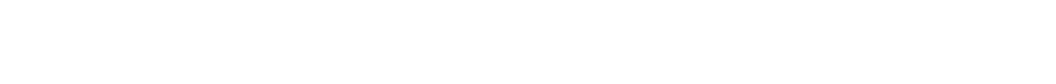

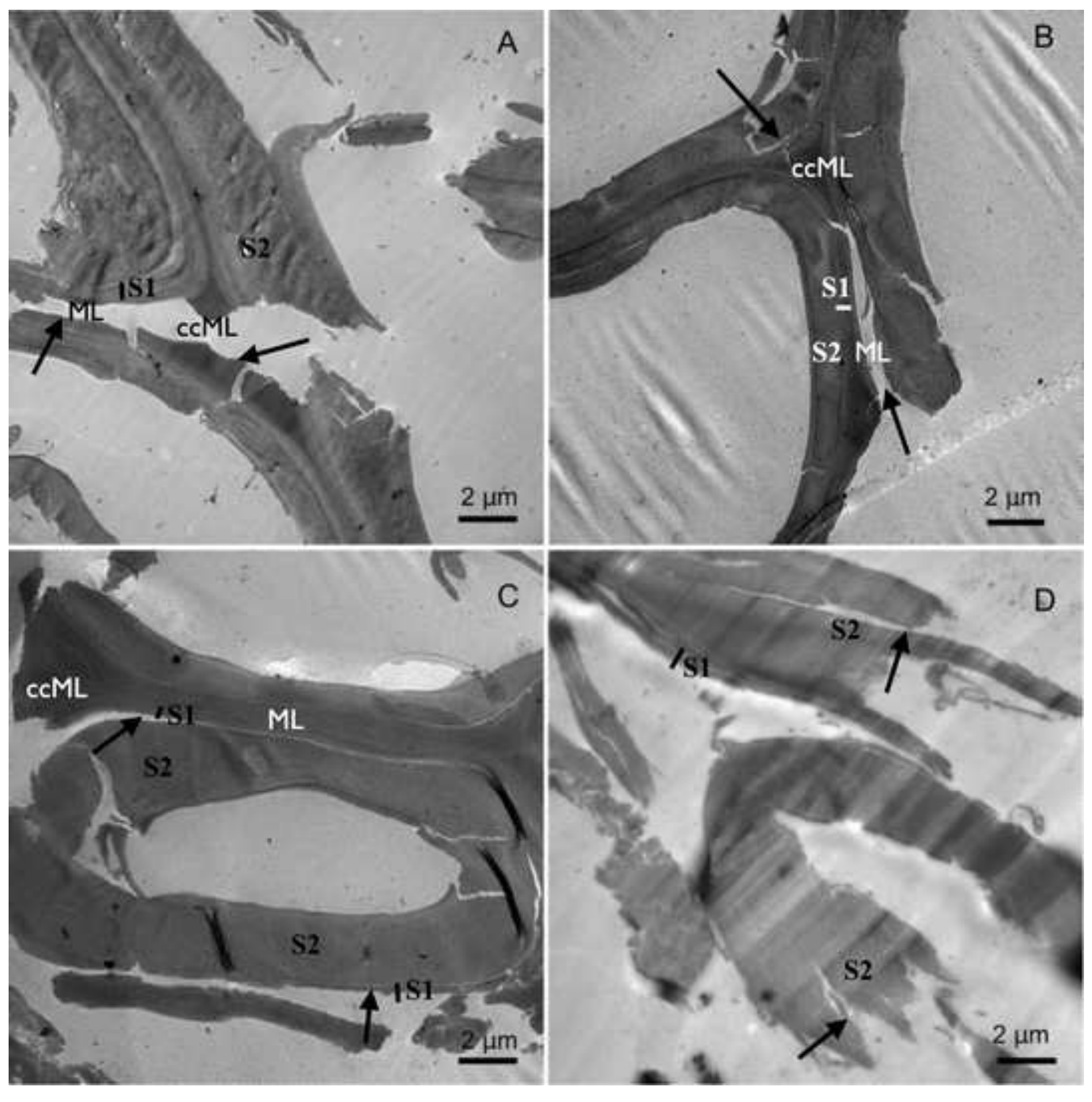

Figure 6

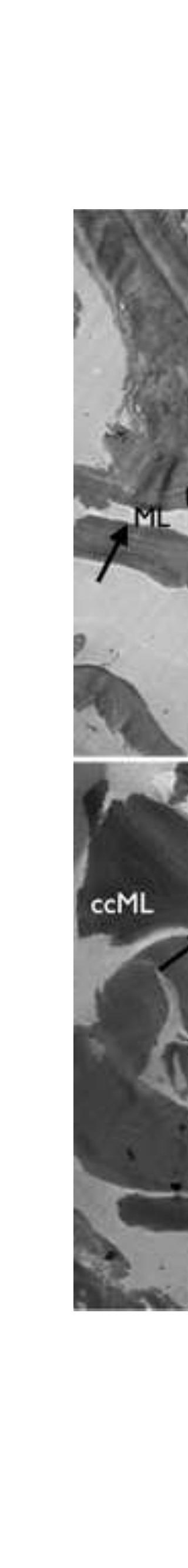

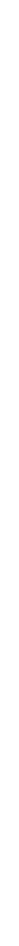




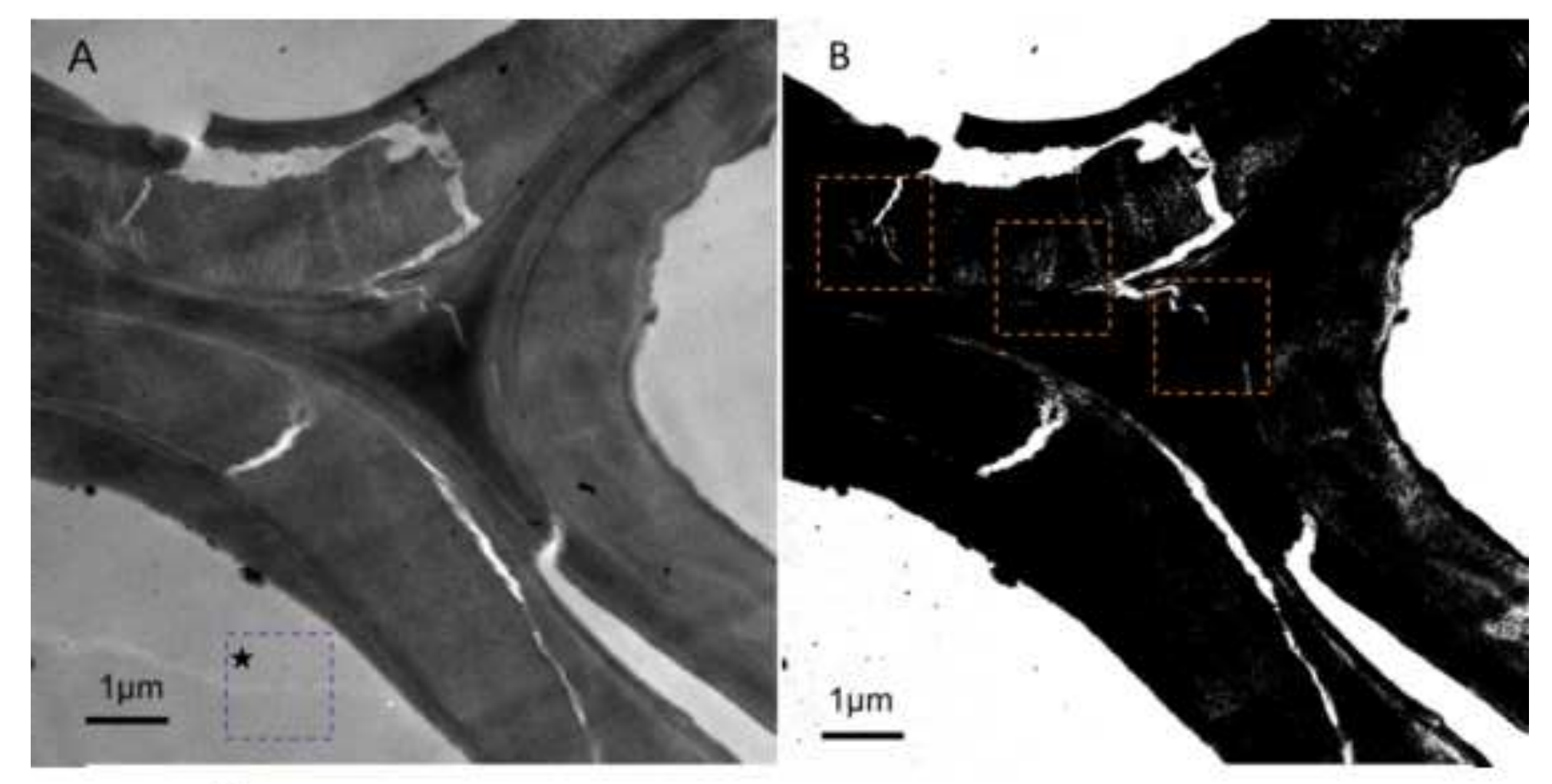

C

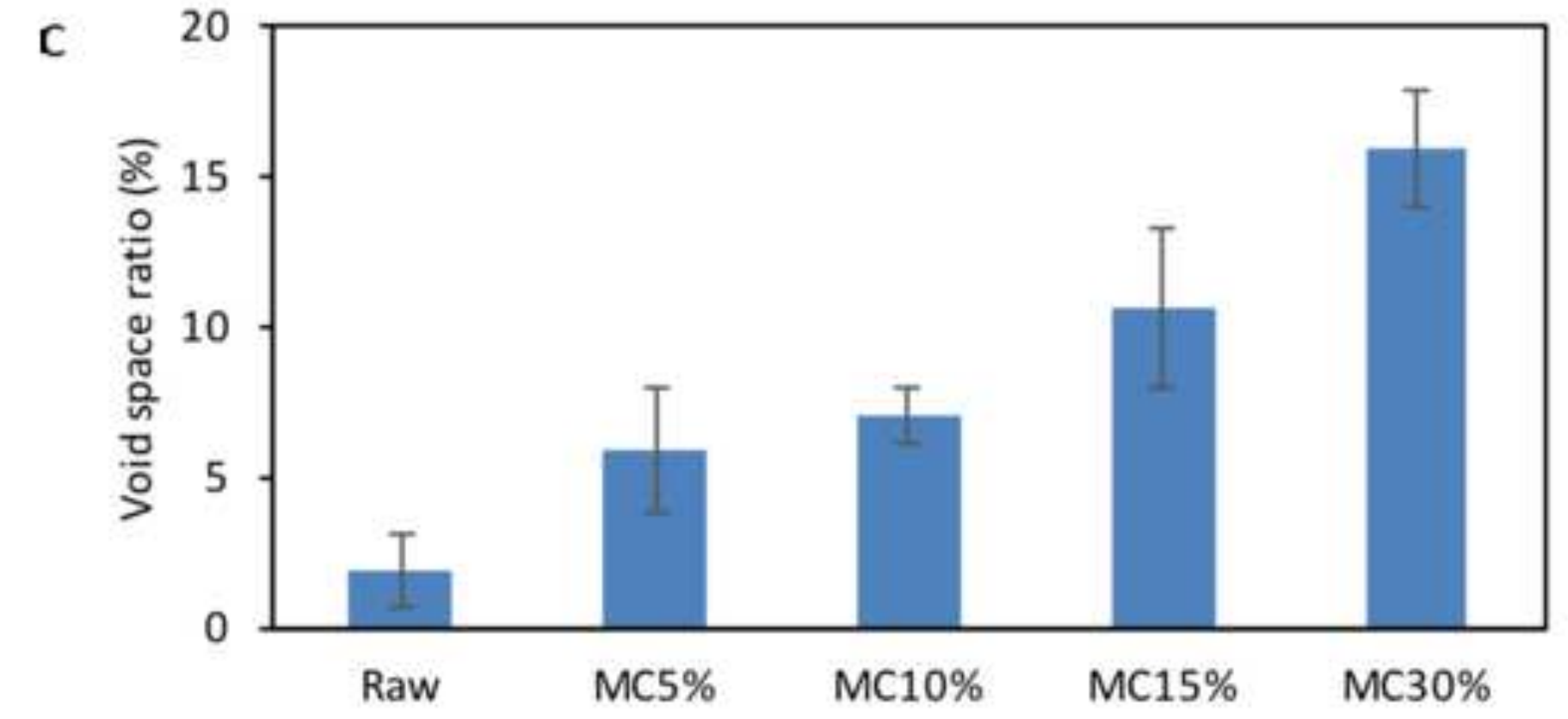

.

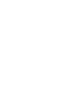

